Article

\title{
Why the Carbon-Neutral Energy Transition Will Imply the Use of Lots of Carbon
}

\author{
Jan Mertens ${ }^{1,2}$, , Ronnie Belmans ${ }^{3,4}$ and Michael Webber ${ }^{1,5}$ \\ 1 ENGIE Research, 1 pl. Samuel de Champlain, Paris-la Défense, 92930 Paris, France; \\ michael.webber@engie.com \\ 2 Department of Electromechanical, system and metal engineering, Ghent University, \\ Technologiepark Zwijnaarde 131, 9052 Zwijnaarde, Belgium \\ 3 Electrical Energy and Computer Architectures, K.U. Leuven, Kasteelpark Arenberg, 3001 Leuven, Belgium; \\ ronnie.belmans@esat.kuleuven.be \\ 4 EnergyVille, Thor Park 8310, 3600 Genk, Belgium \\ 5 Department of Mechanical Engineering, The University of Texas at Austin, 204 E. Dean Keeton St., \\ Stop C2200, Austin, TX 78712-1591, USA \\ * Correspondence: mertensja@yahoo.co.nz; Tel.: +32-473-33-70-22
}

Received: 22 May 2020; Accepted: 6 June 2020; Published: 10 June 2020

\begin{abstract}
This paper argues that electrification and gasification go hand in hand and are crucial on our pathway to a carbon-neutral energy transition. Hydrogen made from renewable electricity will be crucial on this path but is not sufficient, mainly due to its challenges related to its transport and storage. Thus, other 'molecules' will be needed on the pathway to a carbon-neutral energy transition. What at first sight seems a contradiction, this paper argues that carbon (C) will be an important and required chemical element in many of these molecules to achieve our carbon neutrality goal. Therefore, on top of the "Hydrogen Economy" we should work also towards a "Synthetic Hydrocarbon Economy", implying the needs for lots of carbon as a carrier for hydrogen and embedded in products as a form of sequestration. It is crucial that this carbon is taken from the biosphere or recycled from biomass/biogas and not from fossil resources. Due to efficiency losses in capturing and converting atmospheric $\mathrm{CO}_{2}$, the production of renewable molecules will increase the overall demand for renewable energy drastically.
\end{abstract}

Keywords: carbon capture and utilization; hydrogen; energy transition; renewable energy; green electricity; green gas

\section{Introduction}

In its 2019 World Energy Outlook [1], the International Energy Agency (IEA) states that the global energy-related $\mathrm{CO}_{2}$ emissions must decline rapidly and drop from around $33 \mathrm{Gt} / \mathrm{y}$ today to reach $25 \mathrm{Gt} / \mathrm{y}$ in 2030, reduce to under $10 \mathrm{Gt} / \mathrm{y}$ in 2050, and reach net zero in 2070. This trajectory is consistent with a $66 \%$ chance of limiting the temperature rise to $1.8^{\circ} \mathrm{C}$ or a $50 \%$ chance of a $1.65{ }^{\circ} \mathrm{C}$. To achieve these goals, a lot of attention has been paid to the decarbonization of the electricity production-mainly by introducing huge amounts of intermittent renewable power generation such as wind and solar resources [2]. The widespread adoption of digital tools (such as demand side management, for example) will enable the integration of these resources into the grid. There are challenges to this overall idea, though it is without a doubt that renewables and smarter grid management tools will form the basis of the future electric energy system. The energy system is much broader than the electricity system and covers all types of energy vectors, including gas and liquid fuels used for industrial processes, heating of buildings, and mobility. 
Compared with overall energy use, electricity is a limited but very important part [3]. When looking at Europe, for example, the gross generation of electric energy is today around 3255 TWh, while 18,154 TWh of energy is used and thus only $17.8 \%$ of the total energy consumed is delivered in the form of electricity. Given the second law of thermodynamics, the direct use of electric energy is more efficient than converting electricity to other forms, such as chemical or thermal energy. Those conversions reduce the quality or the energy, i.e., its capacity to deliver work. However, for many energy services in industrial value chains (steel, chemistry, mobility, energy, etc.) it is hard to use electricity directly, and therefore 'Molecules' will be needed. What at first sight seems a contradiction, this paper argues that carbon (C) will be an important and required chemical element in many of these molecules to reach a carbon-neutral future.

\section{Why Molecules?}

The underlying reasons why we will need molecules on top of massive amounts of renewable electricity are related to the technical challenges of (i) electricity storage (in particular over longer periods, e.g., seasonal storage), (ii) electricity transport (especially over long distances, e.g., between continents) and (iii) the very low energy density of today's battery storage options. Figure 1 summarizes the volumetric energy issue by illustrating the volumes needed to store or transport $10 \mathrm{kWh}$ of energy using different energy vectors: battery electricity, hydrogen (liquid or at pressure), liquid ammonia $\left(\mathrm{NH}_{3}\right)$, LNG (liquefied natural gas), and petrol (representing a wide variety of hydrocarbons). Table 1 complements this figure by not only giving the numbers for the volumetric energy density but also the gravimetric energy density or specific energy of the different energy vectors.

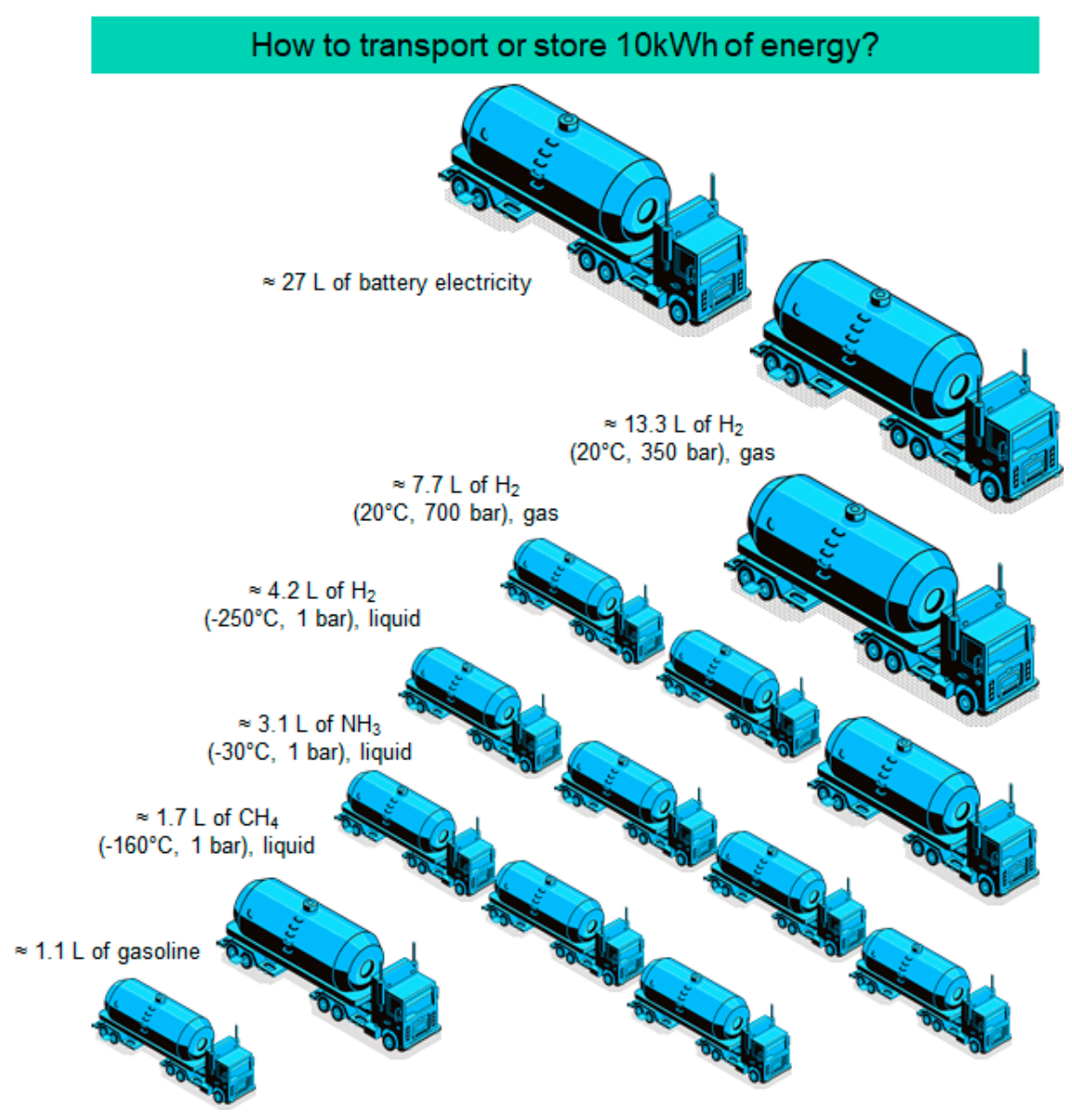

Figure 1. Transport or storage volume of $10 \mathrm{kWh}$ of energy using different energy carriers. 
Table 1. Specific energy and energy density of energy carriers.

\begin{tabular}{|c|c|c|}
\hline Energy Carrier & Specific Energy & Energy Density \\
\hline & $\mathrm{kWh} \mathrm{kg}^{-1}$ & $\mathrm{kWh} \mathrm{L}^{-1}$ \\
\hline Li-ion Battery electricity (average value) & 0.3 & 0.5 \\
\hline Methanol & 5.5 & 4.3 \\
\hline Methane $\left(1 \mathrm{~atm}, 15^{\circ} \mathrm{C}\right)$ & 15.4 & 0.01 \\
\hline Liquified Natural Gas (LNG) $\left(\right.$ at $\left.-160^{\circ} \mathrm{C}\right)$ & 14.9 & 6.2 \\
\hline Liquid $\mathrm{NH}_{3}$ & 5.2 & 3.2 \\
\hline Jet Fuel & 11.9 & 9.7 \\
\hline Hydrogen liquid (LHV) & 33.3 & 2.4 \\
\hline Hydrogen at $1 \mathrm{~atm} @ 15.5^{\circ} \mathrm{C}(\mathrm{LHV})$ & 33.3 & 0.003 \\
\hline Hydrogen at $690 \mathrm{~atm} @ 15.5^{\circ} \mathrm{C}(\mathrm{LHV})$ & 33.3 & 1.2 \\
\hline Gasoline & 12.9 & 9.5 \\
\hline
\end{tabular}

The higher the energy density values listed in Table 1, the more useful a carrier becomes as an energy service supplier: they become easier to store and transport, making them convenient to include in mobile applications. Current battery technologies are not energy dense as compared to typical 'molecules'. Storing large amounts of energy by batteries would imply enormous volumes and weights.

The easiest molecule to be made from renewable electricity is green hydrogen (at an efficiency of today around $70 \%$ ). Hydrogen is also the building block for other molecules-the so-called hydrogen carriers such as methane $\left(\mathrm{CH}_{4}\right)$, ammonia $\left(\mathrm{NH}_{3}\right)$, methanol $\left(\mathrm{CH}_{3} \mathrm{OH}\right)$, and formic acid $\left(\mathrm{CH}_{2} \mathrm{O}_{2}\right)$ - that could be used for chemicals, energy storage, and energy transport. The characteristics of hydrogen are therefore worth a discussion. In a fully decarbonized society, the need for hydrogen produced from carbon free resources is going to be massive to meet the needs of industrial heat, chemicals, and mobility while also serving as a storage medium for excess electricity generated in remote locations. Wherever possible, the direct use of hydrogen at the production site is the preferred option. However, in many cases this will not be possible since the production of hydrogen will mainly be in areas with abundant cheap renewable electricity that do not necessarily coincide with large industrial areas (with steel, cement, chemical, glass facilities, etc.) where enormous energy demands exist. In that case, just as we do today, energy will need to be transported over short and long distances.

Under normal conditions, the volumetric density of hydrogen is extremely low, requiring enormous volumes for storage and flows in pipes. Increasing pressure up to 700 bar can relieve these problems somewhat, but it remains one-eighth the density of gasoline, which inhibits its utility for transport. Moreover, the low boiling temperature of hydrogen $\left(-255^{\circ} \mathrm{C}\right)$ makes its liquefaction energy intensive compared to LNG (liquefied natural gas). Furthermore, the low boiling temperature of hydrogen and reactivity creates non-trivial challenges for the materials used in containments, pumps and compressors [4]. Particularly for domestic applications, these challenges together with hydrogen's high flammability can create safety issues that need to be addressed. Other molecules will therefore be useful carriers to transport these enormous volumes of energy. In that lens, hydrogen remains crucial but mainly as an (important) precursor for manufacturing the final fuel used in specific energy services and feedstock to industry.

\section{Carbon in Molecules for Mobility}

One pressing discussion by policymakers is whether in future mobility will use electricity, hydrogen, biogas, synthetic gaseous or liquid hydrocarbons as its energy source [5]. In fact, we anticipate a suite of fuels will be used for different mobility requirements. The contemporary role of molecules is most obvious if we look at the transport sector, although various traffic modii in the future will be compatible with a range of approaches. The first modus is the "two wheeled". Electric bikes are 
becoming very popular, including high speed ones. The electrical energy need for such a high-speed electrical bike is 500 to $600 \mathrm{Wh}$ whilst the energy need for the more traditional electric bikes is somewhat smaller. This two-wheeled mobility modus will not need molecules. The same holds for other light-duty vehicles such as electric cars for personal mobility. When specifically comparing to hydrogen, thanks to their higher round-trip energy efficiency and their ability to leverage established infrastructure, battery-electric cars and bike-likes have developed a cost advantage in individual mobility, which fuel cell vehicles are unlikely to achieve. As a result, using hydrogen in passenger cars is not a predetermined outcome [6] and the following decade will have to show whether it will find its way to the market, but many of the car manufacturers are giving up further developments.

The future of the heavy freight road transport is not clear yet. High-power electric trucks have been introduced (e.g., Tesla Semi [7] or Nikola [8]) whilst Siemens [9], for example, proposes highways using a catenary electricity line to tap electricity from the grid. The battery will in this concept only be used for the miles driven off the highway. The need for molecules may even here become low or even vanish. A different approach may be seen for long distance transport and supply of urban areas.

For long distance buses, and freight trains or trains on non-electrified railway lines, molecules may remain the best energy source. For heavily used transport systems (almost continuously like forklifts or public transport buses), molecules may be interesting as charging of batteries may take too much time during the active operations and require too much space for charging spares. In fact, one of the most successfully early applications of hydrogen mobility is in forklifts at warehouses for these reasons. Inland shipping electrification projects are under development (e.g., by a consortium with Heineken, ENGIE and the port of Rotterdam amongst others [10]), although it remains somewhat unclear whether batteries will be able to carry sufficient energy to cover long trips, while not requiring too much space on the ship. Again, molecules may play a beneficial role here, in particular for seaborne shipping: batteries will struggle to meet such energy demand and molecules will be required. A back-of-the-envelope calculation [11] reveals that to have an electric ship whose batteries and motors weigh no more than the fuel (about 5000 metric tons) and the diesel engine (about 2000 metric tons) in today's large container vessels, we would need batteries with an energy density more than 10 times as high as today's best Li-ion units. Over the past 70 years, the energy density of the best commercial batteries has not even quadrupled.

For long distance aviation, energy-dense fuels are required and thus molecules will be essential. Some first steps have already been taken towards short haul small electric airplanes [12], some of them running on hydrogen [13]. It seems unlikely that long distance aviation will run on hydrogen as fuel for propulsion, due to its low volumetric energy content. Running long distance planes on hydrogen will increase the volume of fuel tanks significantly (even using liquid $\mathrm{H}_{2}$ ) and aerodynamics is crucial for aviation. There are different molecules available, all having pro and cons, and it is unclear if synthetic kerosene will remain dominant. Again, large amounts of renewable electricity will be needed to produce these molecules.

\section{Carbon in Molecules for Energy Transport over Long Distances}

Hydrogen holds great promises as a fuel and chemical feedstock-but not necessarily as an energy carrier [14]. Green hydrogen, that is hydrogen that is not produced from carbon-based fuels, and synthetic fuels will be key to decarbonizing large sectors of the global economy, making them a critical component in efforts to limit global warming to below $2{ }^{\circ} \mathrm{C}$. This renewable energy will be crucial not only for mobility, but also for industries such as chemistry, petrochemistry, steel, cement, pulp and paper. As mentioned earlier, the need for energy transport will remain important in the energy transition and it will imply moving (renewable) energy from places where it is abundant and cheap (e.g., with abundant solar irradiation) to areas where demand is high (e.g., highly populated areas and industrial clusters). Both the Sahara Desert and Australia are considered to be potential sources of significant solar electricity. It is evident that electricity is not an option to bring renewable energy from Australian to North America or Europe. To bring the energy to Europe from the Sahara, two possibilities 
exist in principle: HVDC electrical transport or chemical energy, i.e., molecules. Many authors look in the direction of hydrogen when considering molecule-based energy transport. However, it has to be analyzed whether this is, energy-wise, including the quality of energy, the best option.

When the hydrogen molecule route is chosen, an electrolyzer is used as a first step, to produce $\mathrm{H}_{2}$ out of $\mathrm{H}_{2} \mathrm{O}$. The availability of water in the Sahara or any desert-type environment may be a major challenge but is not considered here. The efficiency for electrolysis is assumed to be $70 \%$. Cryogenic transport with ships is the most efficient way to bring the hydrogen to Europe. Due to the extremely low boiling temperature of hydrogen $\left(-255^{\circ} \mathrm{C}\right)$, its liquefaction is very energy demanding. Different values are found in the literature, but here a value of $70 \%$ is assumed for this step. The energy use for transport is estimated at $10 \%$, i.e., an efficiency of $90 \%$. This efficiency includes the energy needed to bring the hydrogen by pipes to the coast where liquefaction takes place. The evaporation requires another $5 \%$ of energy leading to an overall efficiency of around $40 \%$. Upon reaching the country of destination, it may be injected in the natural gas grid (up to $20 \%$ by volume has already been demonstrated) and delivered to the final consumer or alternatively and, where available, transport can be done using a hydrogen gas grid. A major challenge related to this hydrogen pathway apart from the low efficiency is the absence of existing infrastructure: no $\mathrm{H}_{2}$ liquefaction plants exist today, the shipping has only recently been demonstrated at a small scale by Kawasaki and partners [15], no $\mathrm{H}_{2}$ gasification plants exist and very limited $\mathrm{H}_{2}$ gas pipeline networks exist worldwide. The rollout of this full infrastructure implies huge costs which come on top of the large volumes of energy consumed in the transport process itself.

An alternative route is to convert the hydrogen using $\mathrm{CO}_{2}$ captured from industry or the air into methane as a hydrogen carrier. It is true that this does not reduce the overall $\mathrm{CO}_{2}$ emissions as $\mathrm{CO}_{2}$ will be emitted again after it is combusted, but it could displace another combustion process using fossil gas. However, this pathway does prevent the exploration and mining of additional 'new' fossil fuels which would have been the case in the absence of the renewable synthetic fuel. To assure carbon neutrality and thus in order to achieve the neutral carbon energy transition, it is crucial the $\mathrm{CO}_{2}$ is either from biogenic nature or captured from the air. Atmospheric $\mathrm{CO}_{2}$ capture was long time considered (and it still is by many) as a nonsense technology, since the low $\mathrm{CO}_{2}$ concentrations in the ambient air present formidable thermodynamic challenges with capture and concentration. Energy consumption as well the footprint of the contactors remain challenging, but this field is flush with research activity and significant cost reductions have been proposed. Low temperature Direct Air Capture (DAC) systems are favorable due to lower heat supply costs and the possibility of using waste heat from other systems. $\mathrm{CO}_{2}$ capture costs of Low Tempertaure DAC systems powered by renewable electricity systems (no waste heat) are expected to drop from over $200 \mathrm{EUR} /$ ton of $\mathrm{CO}_{2}$ today to around $50 \mathrm{EUR} /$ ton of $\mathrm{CO}_{2}$ by 2050 [16].

The efficiency of the process (producing hydrogen followed by methanation) is estimated today to be at $60 \%$. Methane liquefaction is far more efficient than $\mathrm{H}_{2}$ liquefaction, with an efficiency around $95 \%$. LNG transport has a boil-off of round $0.1 \%$ per day, assume one month per round trip, this would lead to around $3 \%$ losses, while the evaporation efficiency is around at $99 \%$. This leads to an overall efficiency of $53.1 \%$ to produce and move $\mathrm{CH}_{4}$ manufactured from renewable electricity. This pathway has the advantage that, on top of a much higher efficiency than the $\mathrm{H}_{2}$ pathway, the infrastructure exists today: LNG liquefaction plants, LNG terminals and ships, and probably most importantly, an existing methane gas transport grid are already in place globally, which presents an opportunity to leverage prior investments, thereby reducing the cost of decarbonization. It is important to minimize methane emissions all along the production, storage, transport and use stage since methane has a much higher global warming potential than $\mathrm{CO}_{2}$ for example.

Of the various possible carriers, $\mathrm{NH}_{3}$ is also studied by many and put forward as a viable molecule for long-distance energy transport. As shown in Table 1, its energy density is much better than hydrogen but lower than hydrocarbons. Although we know how to safely handle the toxicity and transport of $\mathrm{NH}_{3}$ over long distances from an existing and extensive market for agricultural fertilizers, 
industrial processes do not use $\mathrm{NH}_{3}$ as energy source today, and thus significant downstream industrial equipment modifications as well as safety measures are required [17].

Other energy carriers are also studied and Liquid Organic Hydrogen Carriers (LOHC) are often presented as a solution. Apart from their low efficiencies, many of these LOHC's are toxic and not a lot is known on their degradation over time and which other organic compounds could be formed that are possibly even more toxic [18]. Hydrogenation of these LOHC's is an exothermic process and thus energy becomes available at the hydrogen production site, which is usually at a location where renewable energy is abundant and cheap. In contrast, dehydrogenation at the country of destination is an endothermic process and a similar amount of energy is now required in the form of heat (high temperature often above $300^{\circ} \mathrm{C}$ ) at a location where energy is already scarce, which is thus challenging. Metal fuels (i.e., very fine metal powder) [19] are also discussed for long-distance energy transport: metal powder combustion is highly exothermic and thus metal fuel is an energy dense way to transport energy. The oxidation as well as the reduction step from the metal oxide back to the pure metal state (e.g., using hydrogen) are processes that are today immature and only available at lab scale.

Some industry sectors such as chemistry, steel, cement, paper, etc., might need molecules, other than $\mathrm{H}_{2}$, for specific processes. IN addition, for seasonal renewable energy storage, electricity nor hydrogen are viable pathways due to their low energy densities, as presented above. Renewable synthetic methane is a good alternative for many of the industrial processes as well as for storage. However, other $\mathrm{C} 1$ molecules such as for example methanol or formic acid will be part of the solution as well as some $\mathrm{C} 2$ molecules such as ethanol, ethane, dimethylether, etc. To offer climate benefits, these molecules will have to be produced from renewable electricity or from carbon-neutral biogas. In principle there are two sources of carbon-neutral sources of molecules to be used in a carbon-neutral system: those made from water and $\mathrm{CO}_{2}$, captured from the air or from industrial processes, and transformed into useful molecules using green energy at the one hand, and biomass-based molecules at the other. The latter is not discussed in this paper but will surely be part of the solution.

\section{Conclusions}

The interesting thing about energy discussions is that one does not need to have expertise in the field to have a strong opinion. The reason, of course, is that energy is so present in our daily lives, and is critical to move society. Energy enables a high quality of life and, if properly done, makes humans healthy, wealthy and free. In fact, it enables our access to clean water and healthy food as well. In many of these entertaining energy discussions, people seem to dominantly think in opposing ideas: with "either/or" debates about nuclear or gas turbines to complement intermittent renewable electricity production, electricity or gas to produce heat, Li-ion batteries or Redox flow batteries for grid stabilization, electricity or hydrogen mobility, biogas or synthetic methane, etc. Throughout this paper, we argue that these discussions should not exclude carbon-based carriers on the path to zero carbon.

A very popular discussion amongst experts is whether we should electrify or gasify our industry as we move towards a carbon-neutral world. This paper defends strongly the argument that in fact we should do both. Electricity has important advantages over gas and turning electricity into gas reduces efficiency and increases costs. Therefore, wherever possible, the direct and local use of renewable electricity is most efficient and should be the preferred option. However, we may need to pay this conversion price of transforming electricity into molecular form to make energy storable over longer periods or make it more energy dense to transport and use existing transport and conversion infrastructure. In fact, when introducing technologies such as P2G (Power to Gas) and P2G2P (Power to Gas to Power), the distinction between electricity and gas becomes blurred as they are converted back and forth. Then, the discussion whether we should electrify or gasify energy supplies makes little sense since-we will need to do both. What is sure is that, due to efficiency losses in the (atmospheric) $\mathrm{CO}_{2}$ capture and conversion steps, the production of renewable molecules will increase the overall demand for renewable energy drastically. 
Today, almost all approaches to synthesize renewable fuels are more expensive in comparison to their fossil alternatives [20]. If the extrapolation of the past exponentially reducing costs of photovoltaics $(\mathrm{PV})$ and wind electricity continues in future, optimistic scenarios show competitive costs for renewable hydrogen production already in 2027 and for renewable synthetic fuels soon after [14]. Studies show that the cost of the renewable fuel is dominated by the cost of this green hydrogen production, i.e., the operational expenditure (OPEX)related to the renewable electricity production and the Capital expenditure (APEX) of the electrolyzer, which is still expensive today [21].

The paper argues that we should not only work towards a pure "Hydrogen Economy" but also increase our efforts towards a "Synthetic Hydrocarbon Economy". To achieve the carbon-neutral energy transition, we will need lots of carbon. This transition is built on the two closed clean natural cycles of water and $\mathrm{CO}_{2}$ or hydrogen and carbon [8]. It is crucial that this carbon is taken from the biosphere or recycled from biomass/biogas and not from fossil resources but, if done, the "Synthetic Liquid Hydrocarbon Economy" will be as environmental beneficial, while more efficient than a "Pure Hydrogen Economy".

Author Contributions: Writing—original draft preparation, J.M. and R.B.; writing—review and editing, M.W. All authors have read and agreed to the published version of the manuscript.

Funding: This research received no external funding.

Acknowledgments: The authors wish to thanks ENGIE's scientific council for the useful discussions and insights leading to this publication.

Conflicts of Interest: The authors declare no conflict of interest.

\section{References}

1. IEA. World Energy Outlook 2019; IEA: Paris, France, 2019. Available online: https://www.iea.org/reports/ world-energy-outlook-2019 (accessed on 9 June 2020).

2. Van Geem, K.M.; Galvita, V.V.; Marin, G.B. Making chemicals with electricity. Science 2019, 24, 734-735. [CrossRef] [PubMed]

3. Belmans, R.; Mertens, J. The need for molecules in the zero-carbon energy transition. Pour la Science 2020, 6-9.

4. Yin, L.; Ju, Y. Review on the design and optimization of hydrogen liquefaction processes. Front. Energy 2019, 13, 1-15. [CrossRef]

5. Van Mierlo, J.; Messagie, M.; Rangarajua, S. Comparative environmental assessment of alternative fueled vehicles using a life cycle assessment. Transp. Res. Procedia 2017, 25, 3435-3445. [CrossRef]

6. Hegnsholt, E.; Klose, F.; Burchardt, J.; Schönberger, S. The Real Promise of Hydrogen. BCG, 31 July 2019. Available online: https://www.bcg.com/publications/2019/real-promise-of-hydrogen.aspx (accessed on 9 June 2020).

7. Available online: https://www.tesla.com/semi (accessed on 9 June 2020).

8. Available online: https://nikolamotor.com/motor (accessed on 9 June 2020).

9. Available online: https://press.siemens.com/global/en/feature/ehighway-solutions-electrified-road-freighttransport (accessed on 9 June 2020).

10. Available online: https://en.portnews.ru/news/296796/ (accessed on 9 June 2020).

11. IEEE Spectrum. Electric container ships are a hard sail. In IEEE Spectrum; IEEE: Piscataway, NJ, USA, 2019; Volume 56, p. 22.

12. Available online: https://www.airbus.com/innovation/future-technology/electric-flight.html (accessed on 9 June 2020).

13. Available online: https://www.zeroavia.com/ (accessed on 9 June 2020).

14. Bossel, U.; Eliasson, B. Energy and the Hydrogen Economy. Available online: https://afdc.energy.gov/files/ pdfs/hyd_economy_bossel_eliasson.pdf (accessed on 9 June 2020).

15. Kamiya, S.; Nishimura, M.; Harada, E. Study on Introduction of $\mathrm{CO}_{2}$ Free Energy to Japan with Liquid Hydrogen. Phys. Procedia 2015, 67, 11-19. [CrossRef]

16. Fasihi, M.; Efimova, O.; Breyer, C. Techno-economic assessment of $\mathrm{CO}_{2}$ direct air capture plants. J. Clean. Prod. 2019, 224, 957-980. [CrossRef] 
17. Miura, D.; Tezuka, T. A comparative study of ammonia energy systems as a future energy carrier, with particular reference to vehicle use in Japan. Energy 2014, 68, 428-436. [CrossRef]

18. Markiewicz, M.; Zhang, Y.Q.; Bosmann, A.; Bruckner, N.; Thoming, J.; Wasserscheid, P.; Stolte, S. Environmental and health impact assessment of Liquid Organic Hydrogen Carrier (LOHC) systems-challenges and preliminary results. Energy Environ. Sci. 2015, 8, 1035-1045. [CrossRef]

19. Bergthorson, J.M.; Goroshin, S.; Soo, M.J.; Julien, P.; Palecka, J.; Frost, D.L.; Jarvis, D.J. Direct combustion of recyclable metal fuels for zero-carbon heat and power. Appl. Energy 2015, 160, 368-382. [CrossRef]

20. Detz, R.J.; Reek, J.N.H.; van der Zwaan, B.C.C. The future of solar fuels: When could they become competitive? Energy Environ. Sci. 2018, 11, 1653-1669. [CrossRef]

21. Umwelt, Bundesamt, 2016: Power-to-Liquids Potentials and Perspectives for the Future Supply of Renewable Aviation Fuel. Available online: http://www.lbst.de/news/2016_docs/161005_uba_hintergrund_ ptl_barrierrefrei.pdf (accessed on 9 June 2020).

(C) 2020 by the authors. Licensee MDPI, Basel, Switzerland. This article is an open access article distributed under the terms and conditions of the Creative Commons Attribution (CC BY) license (http://creativecommons.org/licenses/by/4.0/). 